\title{
Where do children die and what are the causes? Under-5 deaths in the Metro West geographical service area of the Western Cape, South Africa, 2011
}

\author{
A E Reid, ${ }^{1}$ MB ChB, FCPaed (SA), MMed (Paed), DCH (SA); M K Hendricks, ${ }^{1}$ MB ChB, MMed (Paed), MTropPaed (LSTM, UK), DCH (SA); \\ P Groenewald, ${ }^{2} \mathrm{MB}$ ChB, MPH; D Bradshaw, ${ }^{2}$ D Phil (Oxon)
}

${ }^{1}$ Department of Paediatrics and Child Health, Faculty of Health Sciences, University of Cape Town, South Africa

${ }^{2}$ Medical Research Council Burden of Disease Research Unit, Cape Town, South Africa

Corresponding author: A E Reid (reid_dr@yahoo.ie)

Background. Accurate child mortality data are essential to plan health interventions to reduce child deaths.

Objectives. To review the deaths of children aged $<5$ years during 2011 in the Metro West geographical service area (GSA) of the Western Cape Province (WC), South Africa, from routine data sources.

Methods. A retrospective study of under-5 deaths in the Metro West GSA was done using the WC Local Mortality Surveillance System (LMSS), the Child Healthcare Problem Identification Programme (Child PIP) and the Perinatal Problem Identification Programme (PPIP), and linking where possible.

Results. The LMSS reported 700 under-5 deaths, Child PIP 99 and PPIP 252, with an under-5 mortality rate of 18 deaths per 1000 live births. The leading causes of death were pneumonia (25\%), gastroenteritis $(10 \%)$, prematurity $(9 \%)$ and injuries $(9 \%)$. There were 316 in-hospital deaths (45\%) and 384 out-of-hospital deaths (55\%). Among children aged $<1$ year, there were significantly more pneumonia deaths out of hospital than in hospital $(144(49 \%)$ v. $16(6 \%) ; p<0.001)$. Among children aged $1-4$ years there were significantly more injury-related deaths out of hospital than in hospital (43 (47\%) v. $4(9 \%) ; p<0.001)$. In $56(15 \%)$ of the cases of out-of-hospital death the child had visited a public healthcare facility within 1 week of death. Thirty-six $(64 \%)$ of these children had died of pneumonia or gastroenteritis. Conclusions. Health interventions targeted at reducing under- 5 deaths from pneumonia, gastroenteritis, prematurity and injuries need to be implemented across the service delivery platform in the Metro West GSA. It is important to consider all routine data sources in the evaluation of child mortality.

S Afr Med J 2016;106(4):359-364. DOI:10.7196/SAMJ.2016.v106i4.10521

No single, accurate, complete data system for the evaluation of child mortality exists in South Africa (SA). Cause-of-death data are produced from death notification data on the one hand and from in-hospital mortality audit systems on the other. ${ }^{[1-4]}$ There is a lack of data specific to districts and subdistricts, and previous studies based on death notifications have reported a significant proportion of child deaths from ill-defined causes. ${ }^{[1]}$

These data indicate, in general, that the majority of child deaths in SA are secondary to preventable conditions. Infectious diseases such as gastroenteritis and pneumonia, and neonatal conditions such as prematurity and hypoxia, are the leading causes of under- 5 mortality. ${ }^{[1,3,5]}$ In addition, it has been shown that a large proportion of child deaths occur outside hospitals. ${ }^{[4,5]}$

This study reviewed the deaths of children aged $<5$ years in the Metro West geographical service area (GSA) of the Western Cape Province (WC) in 2011 with particular reference to cause and location using routine data sources. It was envisaged that this information could contribute to the identification of priority conditions to inform health planning in the GSA, as well as give insight into the strengths and weaknesses of our routine data systems.

\section{Methods}

The Metro West GSA includes the subdistricts of Klipfontein, Mitchell's Plain, Southern and Western, with an estimated under-5 population of 180814 in 2011. ${ }^{[6]}$ The public healthcare services in 2011 included the two central hospitals of Red Cross War Memorial Children's Hospital (RCWMCH) and Groote Schuur Hospital (GSH), the secondary-level New Somerset Hospital (NSH) and Mowbray Maternity Hospital, three district hospitals, namely Victoria, Wesfleur and False Bay hospitals, and primary healthcare clinics and midwife obstetric units (MOUs). ${ }^{(7)}$

This was a retrospective study of all under- 5 deaths in the Metro West GSA between 1 January and 31 December 2011 using routine data systems, namely the WC Local Mortality Surveillance System (LMSS) ${ }^{[8]}$ the Child Healthcare Problem Identification Programme (Child PIP) and the Perinatal Problem Identification Programme (PPIP) (Table 1).

The LMSS data, obtained from the LMSS in an Excel Version 2013 spreadsheet, included the demographic characteristics of the child and variables describing the death. For out-of-hospital deaths, previous access to public healthcare facilities and when this had occurred was determined using PREHMIS and Clinicom.

The cause of death was reported in terms of the 10th version of the International Classification of Diseases (ICD-10 ${ }^{[9]}$ codes and aggregated to the National Burden of Disease list of causes by the principal investigator (AER). ${ }^{[10]}$

Data on in-hospital under-5 deaths were reviewed for the following hospitals that implemented Child PIP in 2011: NSH and RCWMCH (excluding deaths in the trauma unit and surgical wards). As Child PIP was not implemented at the time, deaths at GSH and Victoria, False Bay and Wesfleur hospitals and private medical institutions could not be reviewed. The deaths of children who lived outside the Metro West GSA but had died in hospitals within the area were excluded from the analysis.

PPIP 2011 data from the following facilities were reviewed: GSH, NSH, Mowbray Maternity, False Bay and Wesfleur hospitals, and 
Table 1. Summary of the data systems used in the study

\begin{tabular}{|c|c|}
\hline Data system & \\
\hline LMSS & $\begin{array}{l}\text { Combines data from death notification forms and the forensic pathology } \\
\text { information system on all deaths both in and out of hospital }\end{array}$ \\
\hline Child PIP & Mortality review tool used to audit child deaths that occur in hospital \\
\hline PPIP & $\begin{array}{l}\text { Mortality review tool used to audit stillbirths and neonatal deaths that occur } \\
\text { in hospital }\end{array}$ \\
\hline PIMSS & $\begin{array}{l}\text { Mortuary-based surveillance system that collates mortality data from } \\
\text { postmortem examinations, police dockets and chemical pathology reports }\end{array}$ \\
\hline $\begin{array}{l}\text { PREHMIS } \\
\text { and Clinicom }\end{array}$ & $\begin{array}{l}\text { Computerised patient record and health management information systems } \\
\text { that record patient visits or admissions to public hospitals and clinics }\end{array}$ \\
\hline
\end{tabular}

Table 3. Leading causes of death in children aged $<5$ years $(N=700)$ in the Metro West GSA in $2011^{*}$

\begin{tabular}{|c|c|c|}
\hline Cause of death & ICD-10 code & $n(\%)$ \\
\hline Pneumonia & J09 - J18, J20 - J22, J86 & $176(25.1)$ \\
\hline Gastroenteritis & A00 - A09, K52 & $72(10.3)$ \\
\hline Prematurity & P01, P07, P23 <6 days, P25 - P28, P52, P80 & $65(9.3)$ \\
\hline Ill-defined & R00 - R94, R96 - R99, Y34 & $59(8.4)$ \\
\hline Congenital abnormalities & Q00 - Q99 & $56(8.0)$ \\
\hline Other natural & Other natural ICD-10 codes $^{\dagger}$ & $49(7.0)$ \\
\hline Sepsis of the newborn & P23 >6 days, P35, P36 & $27(3.9)$ \\
\hline Birth asphyxia & P02, P03, P20, P21, P24, P91 & $20(2.9)$ \\
\hline Respiratory distress syndrome & $\mathrm{P} 22$ & $20(2.9)$ \\
\hline Other injuries & Other injury ICD-10 codes ${ }^{\ddagger}$ & $19(2.7$ \\
\hline Transport accidents & V01 - V99 & $16(2.3)$ \\
\hline Meningitis & G00 - G05, G09, A39 & $14(2.0)$ \\
\hline HIV & B20 - B24 & $14(2.0)$ \\
\hline Sudden infant death syndrome & R95 & $14(2.0)$ \\
\hline Necrotising enterocolitis & P77 & $13(1.9)$ \\
\hline Exposure to fire & X00 - X19 & $13(1.9)$ \\
\hline Septicaemia & A41 & $12(1.7)$ \\
\hline Other neonatal & Other neonatal ICD-10 codes $^{\S}$ & $12(1.7)$ \\
\hline Assault & X85 - Y09 & $8(1.1)$ \\
\hline Tuberculosis & A16, A17 & $7(1.0)$ \\
\hline Malnutrition & $\mathrm{E} 40-\mathrm{E} 46$ & $7(1.0)$ \\
\hline Drowning & W65 - W74 & $7(1.0)$ \\
\hline Total & & $700(100.0)$ \\
\hline $\begin{array}{l}{ }^{*} \text { LMSS data. } \\
\text { 'Other natural ICD-10 codes: A50, B01, B2 } \\
\text { J69, J96, J98, K21, K40, K42, K55, K56, K72 } \\
\text { "Other injuries ICD-10 codes: W19, W54, } \\
\text { 5 Other neonatal ICD-10 codes: P29, P59, P }\end{array}$ & $\begin{array}{l}\text { 1, C74, D43, D57, D82, E05, E72, E88, G80, G93, H66, I40, I } \\
\text { L20. } \\
\text { W78, W84, W87, X49, X59, X70, Y18, Y69. } \\
0 \text {, P96. }\end{array}$ & , I51, I64, J45, \\
\hline
\end{tabular}

Hanover Park, Vanguard, Retreat, Mitchells Plain and Gugulethu MOUs.

The Child PIP and PPIP data were entered into an Excel spreadsheet (version 2013) by AER.

Theoretically, all deaths recorded in the Child PIP data should have also been captured in the LMSS data. Efforts were made to link the Child PIP and LMSS datasets. The hospital number of each case that had been captured in Child PIP was entered into Clinicom to obtain the name of the child. The date of birth was cross-referenced to ensure that the correct child had been identified. The name was then used to link the Child PIP with the LMSS data. Efforts were made to link the PPIP and the LMSS data in the same manner.
Table 2. Demographic characteristics of under-5 deaths $(N=700)$ in the Metro West GSA in 2011*

\begin{tabular}{ll}
\hline & $\boldsymbol{n}(\%)$ \\
\hline Gender & $378(54.0)$ \\
Male & $322(46.0)$ \\
Female & \\
Age category & $183(26.1)$ \\
Early neonatal $(0-7$ days $)$ & $81(11.6)$ \\
Late neonatal $(>7-<28$ days $)$ & $300(42.9)$ \\
$\begin{array}{l}\text { Post-neonatal infant }(\geq 28 \\
\text { days - <1 year) }\end{array}$ & $136(19.4)$ \\
$\begin{array}{l}1 \text { - } 4 \text { years } \\
\text { Residential subdistrict }\end{array}$ & $180(25.7)$ \\
Klipfontein & $233(33.3)$ \\
Mitchell's Plain & $127(18.1)$ \\
Southern & $160(22.9)$ \\
Western & \\
*MSs data. &
\end{tabular}

Ethical approval for the study was obtained from the Human Research Ethics Committee of the University of Cape Town (approval number: HREC REF 308/2013) and the Health Research Department of the WC (approval number: RP129/2013).

Stata 11.1 was used for statistical analyses. The numerical variables were tested for normality using the Shapiro-Wilk test. Numerical variables, not normally distributed, were expressed as medians (interquartile range (IQR)) and categorical variables were expressed as numbers (percentages). Hypothesis testing was done using the $\chi^{2}$ test for categorical variables and the Mann-Whitney $U$-test for numerical variables not normally distributed. A $p$-value of $<0.05$ was considered statistically significant. The under- 5 mortality rate (U5MR) for the GSA was calculated using the number of deaths as a ratio of the number of live births as reported by PREHMIS and expressed per 1000 .

\section{Results}

The under-5 deaths in the Metro West GSA in 2011 reported by the data systems included a total of 700 for the LMSS, 99 for Child PIP and 252 for PPIP.

The City of Cape Town's PREHMIS data system recorded 38933 live births in the Metro West GSA in 2011. Our study found an U5MR of 18 deaths per 1000 live births.

The demographic characteristics of the children who died are summarised in Table 2. The median age at death was 57 days (IQR 5.5 - 230), with the majority of deaths occurring in children aged $<1$ year. 
The leading causes of death in children aged $<5$ were pneumonia and gastroenteritis, which accounted for $35 \%$ of all deaths (Table 3).

Six hundred and thirty-seven deaths (91\%) were from natural and 63 (9\%) from unnatural causes. The majority of unnatural deaths occurred in males $(n=46,73 \%)$ $(p=0.002)$ and children aged $1-4$ years $(n=47,75 \%) \quad(p<0.001)$. The leading causes of unnatural deaths were transport accidents $(n=16,25 \%)$, exposure to fire $(n=13,21 \%)$, assault $(n=8,13 \%)$ and drowning $(n=7,11 \%)$.

In terms of location of death, 316 children (45\%) died in a hospital or nursing home, 19 (3\%) were dead on arrival, and $65(9 \%)$ died at home, $285(41 \%)$ in an unknown location and 15 (2\%) in a location reported as 'other' on the death notification form. Using data from the PIMSS it was possible to confirm that 156 of the deaths reported in an unknown location had occurred outside hospital. In addition, there was no record of any of the 285 deaths occurring in public hospitals in the Metro West GSA according to Clinicom. Of the children 384 (55\%) therefore appeared to have died outside a hospital or nursing home. The median age of these children was 92 days (IQR 37.5 - 338); $211(55 \%)$ were male and 173 (45\%) female.

Table 4 shows a comparison of the leading causes of death in children who died in and out of hospital by age category.

In- and out-of-hospital deaths are compared in Table 5. Statistically significant factors were median age, and death due to pneumonia, gastroenteritis and unnatural causes. Children who died out of hospital were more likely to have an autopsy performed than those who died in hospital.

An autopsy was performed in 217 (31\%) cases. The majority of these cases $(n=154$, $71 \%$ ) died from natural causes and $63(29 \%)$ from unnatural. Of the 202 children who died out of hospital and had an autopsy performed, 144 (71\%) died from natural causes. The leading causes of death in this subgroup were pneumonia $(n=78$, $54 \%)$, ill-defined causes $(n=20,14 \%)$ and gastroenteritis $(n=13,9 \%)$.

Of the 384 children who died out of hospital, 56 (15\%) had visited a public health facility within 1 week of death. The leading causes of death in this group were pneumonia $(n=25,45 \%)$ and gastroenteritis $(n=12,21 \%)$.

\section{The Child PIP data}

Child PIP reported 99 deaths at RCWMCH and NSH of children who lived in the Metro West GSA in 2011. Of the 99 children who died, 56 (57\%) were HIV-negative, 11 (11\%)
Table 4. Leading causes of in- and out-of-hospital deaths by age category in the Metro West GSA in 2011*

\begin{tabular}{|c|c|c|c|}
\hline In-hospital causes of death & $n(\%)$ & Out-of-hospital causes of death & $n(\%)$ \\
\hline $\begin{array}{l}\text { Neonatal deaths } \\
(0-28 \text { days })(N=195)\end{array}$ & & $\begin{array}{l}\text { Neonatal deaths } \\
(0-28 \text { days })(N=69)\end{array}$ & \\
\hline Prematurity & $60(30.8)$ & Pneumonia & $24(34.8)$ \\
\hline Sepsis of the newborn & $27(13.8)$ & Ill-defined & $14(20.3)$ \\
\hline Congenital & $25(12.8)$ & Congenital & $6(8.7)$ \\
\hline Respiratory distress syndrome & $20(10.3)$ & Prematurity & $5(7.2)$ \\
\hline Birth asphyxia & $18(9.2)$ & Assault & $4(5.8)$ \\
\hline Ill-defined & $13(6.7)$ & Other neonatal & $4(5.8)$ \\
\hline Necrotising enterocolitis & $11(5.6)$ & Sudden infant death syndrome & $3(4.3)$ \\
\hline Other natural & $8(4.1)$ & Other injuries & $2(2.9)$ \\
\hline Other neonatal & $8(4.1)$ & Birth asphyxia & $2(2.9)$ \\
\hline Pneumonia & $3(1.5)$ & Gastroenteritis & $1(1.4)$ \\
\hline Septicaemia & $1(0.5)$ & HIV & $1(1.4)$ \\
\hline \multirow[t]{3}{*}{ Sudden infant death syndrome } & $1(0.5)$ & Malnutrition & $1(1.4)$ \\
\hline & & Exposure to fire & $1(1.4$ \\
\hline & & Other natural & $1(1.4)$ \\
\hline $\begin{array}{l}\text { Post-neonatal deaths } \\
(>28 \text { days }-1 \text { year) }(N=77)\end{array}$ & & $\begin{array}{l}\text { Post-neonatal deaths } \\
(>28 \text { days }-1 \text { year) }(N=223)\end{array}$ & \\
\hline Gastroenteritis & $15(19.5)$ & Pneumonia & $120(53.8)$ \\
\hline Pneumonia & $13(16.9)$ & Gastroenteritis & $41(18.4)$ \\
\hline Other natural & $12(15.6)$ & Ill-defined & $20(9.0)$ \\
\hline Congenital & $10(13.0)$ & Other natural & $10(4.5)$ \\
\hline HIV & $9(11.7)$ & Sudden infant death syndrome & $9(4.0)$ \\
\hline Septicaemia & $6(7.8)$ & Congenital & $7(3.1)$ \\
\hline Ill-defined & $5(6.5)$ & Other injuries & $6(2.7)$ \\
\hline Malnutrition & $2(2.6)$ & Meningitis & $2(0.9)$ \\
\hline Necrotising enterocolitis & $2(2.6)$ & Septicaemia & $2(0.9)$ \\
\hline Tuberculosis & $1(1.3)$ & HIV & $2(0.9)$ \\
\hline Sudden infant death syndrome & $1(1.3)$ & Transport accidents & $2(0.9)$ \\
\hline \multirow[t]{2}{*}{ Other injuries } & $1(1.3)$ & Tuberculosis & $1(0.4)$ \\
\hline & & Malnutrition & $1(0.4)$ \\
\hline $1-4$ years $(N=44)$ & & $1-4$ years $(N=92)$ & \\
\hline Other natural & $11(25.0)$ & Transport accidents & $14(15.2)$ \\
\hline Meningitis & $6(13.6)$ & Exposure to fire & $12(13.0)$ \\
\hline Pneumonia & $5(11.4)$ & Pneumonia & $11(12.0)$ \\
\hline Gastroenteritis & $4(9.1)$ & Gastroenteritis & $11(12.0)$ \\
\hline Septicaemia & $3(6.8)$ & Other injuries & $9(9.8)$ \\
\hline Drowning & $3(6.8)$ & Other natural & $7(7.6)$ \\
\hline Ill-defined & $3(6.8)$ & Meningitis & $6(6.5)$ \\
\hline HIV & $2(4.5)$ & Congenital & $6(6.5)$ \\
\hline Malnutrition & $2(4.5)$ & Assault & $4(4.3)$ \\
\hline Tuberculosis & $2(4.5)$ & Drowning & $4(4.3)$ \\
\hline Congenital & $2(4.5)$ & Ill-defined & $4(4.3)$ \\
\hline \multirow[t]{2}{*}{ Other injuries } & $1(2.3)$ & Tuberculosis & $3(3.3)$ \\
\hline & & Malnutrition & $1(1.1)$ \\
\hline
\end{tabular}


were HIV-positive, 10 (10\%) were HIVexposed, and in 22 cases (22\%) the HIV status was unknown.

Thirty-seven children (37\%) were of normal weight, 36 (36\%) were underweight, $16(16 \%)$ had severe malnutrition, 2 (2\%) were overweight and in 8 cases (8\%) the nutritional status was unknown.

The leading causes of in-hospital deaths in children aged 1 - 59 months according to the Child PIP and LMSS datasets are shown in Table 6.

\section{The PPIP data}

PPIP reported 252 neonatal deaths. There were 219 (86.9\%) early neonatal and 33 (13.1\%) late neonatal deaths. The leading causes of in-hospital early and late neonatal deaths according to PPIP and the LMSS data are shown in Table 7.

\section{Discussion}

This study, which reviewed under- 5 deaths in the Metro West GSA in 2011, found a lower U5MR than the 41 - 44 deaths per 1000 live births reported nationally. ${ }^{[1,12]}$

Despite the comparatively low U5MR, this study highlights priority health conditions that need to be addressed at primary care level if under-5 mortality is to be reduced further in the GSA.

Of concern is the high number of out-ofhospital deaths, as confirmed in other studies. ${ }^{[4,5,7]}$ The current practice in the province is to investigate any sudden unexplained child death by postmortem examination. About four times more child deaths are investigated at forensic mortuaries in the WC than elsewhere in the country. ${ }^{[13]}$ This practice provided unique insight into the causes of out-of-hospital child deaths, showing that most of these deaths were from natural causes such as pneumonia and gastroenteritis.

Eighty-eight percent of deaths from pneumonia occurred out of hospital. It is possible that some of these deaths were misclassified as pneumonia when in fact they were secondary to other causes. In approximately half of these cases the cause of death was certified by the forensic pathology services after an autopsy.

The in-hospital mortality rate for pneumonia in the WC is relatively low at $0.6 \% .{ }^{[2]}$ The large numbers of deaths occurring out of hospital secondary to potentially treatable conditions raise concern and indicate that factors such as access to healthcare, health-seeking behaviour and the functioning of the health system in the GSA need to be evaluated.

Fifteen percent of children who died out of hospital had visited a public healthcare facility within 1 week of death. Most of the children in this group were 2-3 months of age and died of pneumonia or gastroenteritis. These visits potentially represent missed opportunities by the health system to recognise severity of illness in young babies, encourage routine follow-up and counsel caregivers with regard to danger signs of illness.

Our study identified a greater proportion of deaths due to pneumonia than has been reported nationally by the vital registration data. ${ }^{[13]}$ This difference may in part be explained by the incorporation of data from the forensic pathology services by the LMSS. This practice has reduced the percentage of ill-defined deaths to $7 \%$ in this study, compared with $13 \%$ in a previous national study based solely on death notification data. ${ }^{[1]}$ By reducing the percentage of illdefined deaths, this study provides more accurate cause-of-death data and in so doing has identified a larger proportion of children dying from pneumonia than previously reported.

We identified a lower percentage of deaths due to gastroenteritis than nationally. ${ }^{[13]}$ This may be explained by improved access to clean water and sanitation ${ }^{[14]}$ and a co-ordinated strategy to deal with the annual diarrhoeal disease surge in the GSA (M K Hendricks, personal communication).

Table 5. Comparison of children who died in and out of hospital in the Metro West GSA in $2011^{*}$

\begin{tabular}{llll}
\hline Variable & $\begin{array}{l}\text { In-hospital deaths } \\
(N=316)\end{array}$ & $\begin{array}{l}\text { Out-of-hospital deaths } \\
(\boldsymbol{N = 3 8 4})\end{array}$ & $\boldsymbol{p}$-value \\
\hline Age (days), median (IQR) & $8.5(1-111)$ & $92(37.5-338)$ & $<0.001$ \\
Male/female ratio & $167: 149$ & $211: 173$ & 0.579 \\
Deaths from unnatural causes, $n(\%)$ & $5(1.6)$ & $58(15.1)$ & $<0.001$ \\
Cases in which an autopsy was & $15(4.7)$ & $202(52.6)$ & $<0.001$ \\
performed, $n(\%)$ & & $155(40.4)$ & $<0.001$ \\
Pneumonia, $n(\%)$ & $21(6.6)$ & $53(13.8)$ & 0.001 \\
Gastroenteritis, $n(\%)$ & $19(6.0)$ & $38(9.9)$ & 0.123 \\
Ill-defined causes of death, $n(\%)$ & $21(6.6)$ & & \\
${ }^{*}$ LMSs data. & & &
\end{tabular}

Table 6. Leading causes of in-hospital deaths in children aged 1 - 59 months in the Metro West GSA in 2011 by data source

\begin{tabular}{llll}
\hline $\begin{array}{l}\text { Leading causes of death, } \\
\text { LMSS }(\mathbf{N = 1 2 1})\end{array}$ & $\boldsymbol{n}(\mathbf{\%})$ & $\begin{array}{l}\text { Leading causes of death, } \\
\text { Child PIP }(\mathbf{N = 8 8})\end{array}$ & $\boldsymbol{n}(\mathbf{\%})$ \\
\hline Gastroenteritis & $19(15.7)$ & $\begin{array}{l}\text { Septicaemia/possible serious } \\
\text { bacterial infection }\end{array}$ & $22(25.0)$ \\
Pneumonia & $18(14.9)$ & Pneumonia & $19(21.6)$ \\
Congenital & $12(9.9)$ & Meningitis: bacterial & $6(6.8)$ \\
HIV & $11(9.1)$ & $\begin{array}{l}\text { Acute diarrhoea, hypovolaemic } \\
\text { shock }\end{array}$ & $4(4.5)$ \\
Septicaemia & $9(7.4)$ & Hospital-acquired infection & $3(3.4)$ \\
Ill-defined & $8(6.6)$ & Neoplasia & $3(3.4)$ \\
Meningitis & $6(5.0)$ & Congenital heart disease & $2(2.3)$ \\
Malnutrition & $4(3.3)$ & Myocarditis & $2(2.3)$ \\
Tuberculosis & $3(2.5)$ & Tuberculous meningitis & $2(2.3)$ \\
Drowning & $3(2.5)$ & Other & $25(28.4)$ \\
Necrotising enterocolitis & $2(1.7)$ & & \\
Other injuries & $2(1.7)$ & & \\
Sudden infant death syndrome & $1(0.8)$ & & \\
Other natural & &
\end{tabular}


Table 7. Leading causes of in-hospital neonatal deaths in the Metro West GSA in 2011 by data source

\begin{tabular}{ll}
\hline & $\boldsymbol{n}(\%)$ \\
\hline PPIP & \\
Obstetric causes of all neonatal deaths $(N=252)$ & \\
Idiopathic preterm labour & $73(29.0)$ \\
No obstetric cause/not applicable & $28(11.1)$ \\
Spontaneous preterm labour & $22(8.7)$ \\
Proteinuric hypertension & $17(6.7)$ \\
Preterm prelabour rupture of membranes & $15(6.0)$ \\
Labour-related intrapartum asphyxia & $15(6.0)$ \\
Abruptio placentae & $14(5.6)$ \\
Syphilis & $7(2.8)$ \\
Amniotic fluid infection & $6(2.4)$ \\
Other infections & $5(2.0)$ \\
Other & $50(19.8)$
\end{tabular}

Early neonatal deaths $(N=219)$

Extreme multiorgan immaturity

Hypoxic ischaemic encephalopathy

Congenital abnormalities

Immaturity related

Pulmonary haemorrhage

Septicaemia

Congenital syphilis

Unknown cause of death

Hyaline membrane disease

Other

$22(10.0)$

$21(9.6)$

$12(5.5)$

$10(4.6)$

$6(2.7)$

$6(2.7)$

$6(2.7)$

$38(17.4)$

Late neonatal deaths $(N=33)$

Necrotising enterocolitis

Extreme multiorgan immaturity

Septicaemia

7 (21.2)

Nosocomial infection

Sudden infant death syndrome

Other

LMSS

Early neonatal deaths $(N=148)$

Prematurity

Congenital

Respiratory distress syndrome

Birth asphyxia

$17(11.5)$

Sepsis of the newborn

$11(7.4)$

Ill-defined

$10(6.8)$

Other natural

Other neonatal

Necrotising enterocolitis

Pneumonia

Septicaemia
Table 7. (continued) Leading causes of in-hospital neonatal deaths in the Metro West GSA in 2011 by data source

\begin{tabular}{ll}
\hline Late neonatal deaths $(N=47)$ & $\boldsymbol{n}(\%)$ \\
Sepsis of the newborn & $16(34.0)$ \\
Necrotising enterocolitis & $7(14.9)$ \\
Prematurity & $7(14.9)$ \\
Congenital & $5(10.6)$ \\
Other neonatal & $4(8.5)$ \\
Ill-defined & $3(6.4)$ \\
Pneumonia & $1(2.1)$ \\
Sudden infant death syndrome & $1(2.1)$ \\
Birth asphyxia & $1(2.1)$ \\
Respiratory distress syndrome & $1(2.1)$ \\
Other natural & $1(2.1)$
\end{tabular}

This study has highlighted the prominence of injury deaths (9\%), especially among male children aged 1 - 4 years. This is a higher proportion of unnatural deaths than reported for children aged under 5 years nationally. ${ }^{[5]}$ While it may reflect better injury data provided by the mortuaries in Cape Town, it nevertheless indicates that injuries are a particular public health concern in the GSA.

It is widely accepted that death notification data under-report HIV-associated deaths. ${ }^{[1,5,13,15]}$ Our study highlighted this point, as the LMSS data reported only $2 \%$ of deaths as due to HIV, in comparison with the Child PIP data, which showed that $21 \%$ of children who died were either HIV-positive or HIV-exposed. However, the HIV status of a large proportion of children who died in hospital was unknown.

Valuable insight has been gained with regard to the utility of different data sources for the evaluation of child mortality. Child PIP and PPIP were designed for the purposes of auditing in-hospital paediatric and neonatal deaths and are adopted by hospitals on a voluntary basis. ${ }^{[1-4]}$ Consequently, from a public health perspective these data are incomplete, as out-of-hospital deaths and those that occur in facilities that have not adopted these audit systems are not evaluated. In addition, Child PIP and PPIP do not necessarily provide the so-called underlying cause of death that resulted in the causal sequence of conditions that should be targeted for prevention. PPIP under-reports late neonatal deaths, as it does not capture deaths that occur after discharge from neonatal units. ${ }^{[3]}$ In addition, it is not possible to extract PPIP data by gender, subdistrict or location of death, as this information is not captured. However, Child PIP and PPIP do provide valuable information with regard to the HIV and nutritional status of children who die in hospital. Furthermore, in this study, Child PIP data from certain district hospitals was not included in the analysis.

The LMSS provides a more complete mortality profile as it reports both in- and out-of-hospital child deaths, but it is hampered by under-reporting of HIV-associated deaths and missing information. If data from the forensic pathology services are not incorporated in cases where the death was certified at forensic mortuaries, the percentage of ill-defined deaths is significant.

The linkage of these data systems on a routine basis may improve the quality of cause-of-death data. Linking Child PIP and PPIP to the LMSS data would improve the accuracy of each dataset by identifying errors in data capturing. In addition, an 
evaluation of the immediate and underlying cause of death as provided by the different data systems would be possible, allowing better understanding of the sequence of events that lead to the death. The linking of Child PIP and PPIP data to the LMSS would improve the reporting of deaths due to HIV and malnutrition. Linkage of the PREHMIS and Clinicom systems, which record public healthcare service visits, to mortality data would allow the routine evaluation of the community's health service utilisation patterns.

\section{Conclusions and recommendations}

Health interventions aimed at reducing under-5 deaths from pneumonia, gastroenteritis, prematurity and injuries need to be strengthened and implemented across the service delivery platform in the Metro West GSA. A priority is reduction in deaths from pneumonia, which account for one out of every four under-5 deaths.

One in every five children who were admitted to and died in a public healthcare facility in the GSA was not tested for HIV. We need to strengthen the policy of HIV counselling and testing for every child admitted to a hospital in the GSA.

There is a need for further research to evaluate why children are dying outside hospital from potentially treatable conditions. This is concerning in an urban area with short distances to healthcare facilities, a documented previous pattern of health-seeking behaviour in many cases, and a relatively low in-hospital mortality rate.

In addition, it is vital to continue to strengthen the data sources that are used for the evaluation of child mortality and to encourage the linkage of routine data sources to gain as accurate a picture of child mortality as possible.

\section{References}

1. Nannan N, Dorrington R, Laubscher R, et al., Burden of Disease Research Unit. Under-5 Mortality Statistics in South Africa: Shedding Some Light on the Trends and Causes 1997-2007. Cape Town: South African Medical Research Council, 2012:1-107.

2. Stephen CR, Bamford LJ, eds. Saving Children 2010-2011: A Seventh Survey of Child Health Care in South Africa. Pretoria: Tshepesa Press, Medical Research Council and Centres for Disease Control and Prevention, 2013:1-142.

3. Pattinson RC. Saving Babies 2010-2011: Eighth Report on Perinatal Care in South Africa. Pretoria: Tshepesa Press, 2013:1-46.

4. National Department of Health. 1st Triennial Report of the Committee on Morbidity and Mortality of Children under 5 Years (CoMMiC): 2008-2010. Pretoria: National Department of Health, 2011. http:// Chwildealther

5. Statistics South Africa. Mortality and Causes of Death in South Africa: Findings from Death Notification 2012. Pretoria: Statistics South Africa, 2014:1-123.

6. Health District Profiles (August 2013). Compiled by Strategic Development Information and GIS Department, City of Cape Town, using 2011 Census data supplied by Statistics South Africa. https:// www.capetown.gov.za/en/stats/Pages/Census2011.aspx (accessed 6 February 2015).

7. Hendricks MK, Nelson C, Linley L, et al. A Situational Analysis of Neonatal and Child Health Status in the Metro West Geographical Service Area of the Western Cape. Cape Town: Western Cape Department of Health, 2012:1-44.

8. Groenewald P, Bradshaw D, Daniels J, et al. Differential health needs of the population in Cape Town, South Africa: Local-level mortality surveillance in resource-limited settings: A case study of Cape Town highlights disparities in health. Bull World Health Organ 2010;88(6):444-451. DOI:10.2471/BLT.09.069435

9. World Health Organization International Statistical Classification of Diseases and Related Health Problems. 10th revision. Geneva: WHO, 1992. http://apps.who.int/classifications/icd10/browse/2015/ en (accessed 26 January 2015).

10. Pillay-Van Wyk V, Laubscher R, Msemburi W, et al. Second South African National Burden of Disease Pillay-Van Wyk V, Laubscher R, Msemburi W, et al. Second South African National Burden of Disease
Study: Data Cleaning, Validation and South African National Burden of Disease List. Cape Town: Burden of Disease Research Unit, South African Medical Research Council, 2014:1-51.

11. Liu L, Oza S, Hogan D, et al. Global, regional and national causes of child mortality in 2000-2013, with projections to inform post 2015 priorities: An updated systematic analysis. Lancet 2015;385(9966):430440. DOI:10.1016/S0140-6736(14)61698-6

12. United Nations Inter-agency Group for Child Mortality Estimation. Levels and Trends in Child Mortality Report 2014. New York: United Nations Children's Fund, 2014:1-36.

13. Statistics South Africa. Mortality and Causes of Death in South Africa 2011: Findings from Death Notification. Pretoria: Statistics South Africa, 2014:1-117.

14. Hall K, Marera D-H. Children’s access to basic services. In: Kibel M, Lake L, Pendlebury S, Smith C, eds. South African Child Gauge 2009/10. Cape Town: Children's Institute, University of Cape Town, 2010:130-132.

15. Kerber KJ, Lawn JE, Johnson LF, et al. South African child deaths 1990-2011: Have HIV services reversed the trend enough to meet Millennium Development Goal 4? AIDS 2013;27(16):2637-2648. DOI:10.1097/01.aids.0000432987.53271.40

Accepted 19 February 2016. 